\title{
Shared Space: Study of Counter-Terrorist Adjustments
}

\section{Anton Ostakh}

Tutor: doc. Ing. arch. Irena Fialová, Ústav urbanismu, Fakulta architektury, České vysoké učení technické v Praze

E-mail address: antonostx@gmail.com

\begin{abstract}
This work is a part of the research being conducted at the Faculty of Architecture of the CTU on the topic of 'Theory of Shared space and its projection on architectural and urban design'. The article deals with the issue of vehicle-borne terrorism attacks in public spaces that are organized according to the principle of the road user's integration - Shared space. Highlighted here are common approaches of protection from vehicle-borne attacks. Particular counter-terrorism measures and tools applicable to spaces like Shared space are specified. The current challenges and threats to the safety of pedestrians on city streets are also outlined in this article.
\end{abstract}

KEYWORDS: Shared space; terrorism; vehicle-borne attack; integrated security; street design; counter-terrorism measures; bollards; autonomous vehicle 


\section{METHODOLOGY}

Great Britain was chosen for studying counter-terrorism measures, where long-time efforts are being made to create safe public spaces, and some examples of Shared spaces have already been put in practice. The basis for the research and this publication were face-to-face interviews with experts in the field of counter-terrorism from the Center for Protection of National Infrastructure (CPNI) and experts in the field of studying Shared spaces from the Chartered Institution of Highways and Transportation. Personal observations in London public spaces, photographs, and accessible publications on this subject were also used.

\section{INTRODUCTION. WHAT IS SHARED SPACE?}

The balance between the residential function and the function of movement in urban spaces has become an acute issue globally.

\section{HLEDÁNÍ ROVNOVÁHY MEZI POBYTEM A POHYBEM VE VEŘEJNÝCH PROSTORECH}

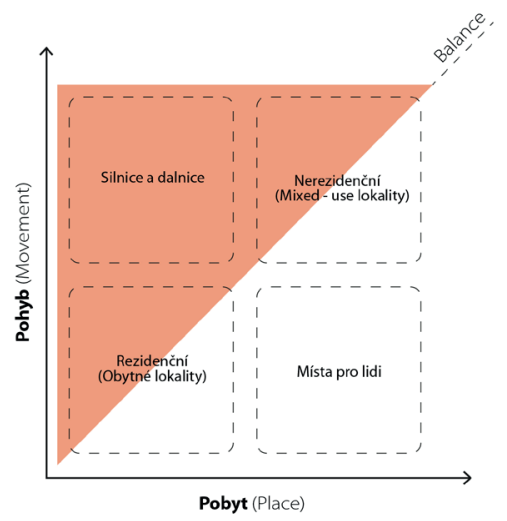

Fig. 1. Finding a balance between place and movement (Source: Author)

In order to reduce the negative impact of transport on urban public spaces, especially in central urban areas, the Shared space theory was developed at the end of the 20 th and in the beginning of the 21st century. This theory describes an approach of calming traffic on city streets or 'a way of thinking about the design process...', in a way that enhances the residential function of urban public spaces. Many cities have already tested this concept, with Prague being no exception. 
removal of all kinds of regulatory and segregating elements of the transport infrastructure (signs, traffic lights, markings, fences, sidewalks, etc.) from the streets and the creation of conditions where pedestrians and, most importantly, drivers begin to adapt their behavior to a specific situation and therefore pay more attention to the environment. This approach of integrating pedestrians and cars into one common space still raises security questions in the face of the threats posed by fast-moving cars that are used by terrorists to attack pedestrians. Such terrorist attacks have recently regained a steady character, primarily in European cities. According to experts, this situation is not temporary and such threats need to be given increased attention in the future (CPNI, 2018).

\section{ZAHRANIČNI PŘIKLADY SDÍLENÝCH PROSTORŮ}
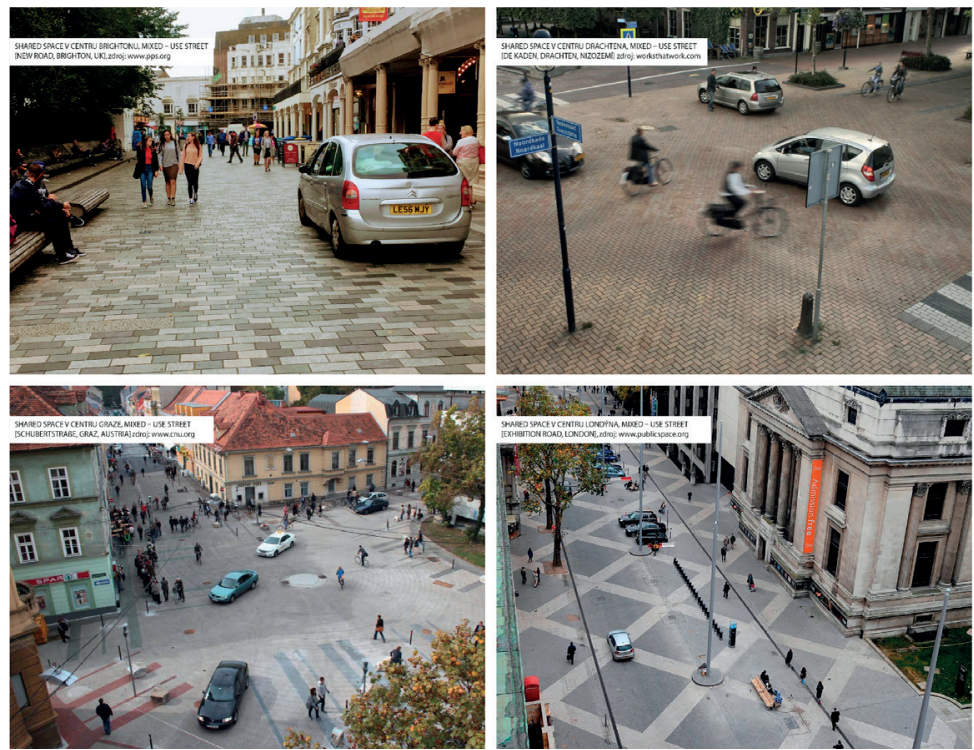

Fig. 2. Examples of Shared spaces (Source: Internet)

\section{THE PROBLEM OF TERORISM IN SHARED SPACE}

The problem of vehicle-borne attacks in public spaces with no rigid segregation between pedestrians and cars is a new challenge. Terrorists choose crowded streets in city centers as their goals. Such central, often rich in history, urban public spaces are difficult to change in any way in order to increase their security, without changing the way that they have traditionally been utilized ${ }^{1}$. This is primarily due to the high requirements for the inclusiveness and accessibility of city streets, and also to 
the requirements for their aesthetic qualities. These qualities are difficult to maintain using existing (often temporary) counter-terrorism measures, where segregation is often the main tool. Such measures not only segregate cars from pedestrians, but also pedestrians from places. In practice, various blocks and barriers are used today in the form of prefabricated concrete and other barriers, which are designed to protect pedestrians from car collisions. Such measures can cause fear in people and destroy the quality of urban spaces. However, life on city streets is based on the integration between the participants of the city theater ${ }^{2}$ and the processes ${ }^{3}$ within it. The main problem can therefore be identified as an urgent social need for new effective solutions for the fight against vehicle-borne attacks on city streets, which would not only maintain their safety, but at the same time preserve the basic principles that make city streets open, attractive and comfortable.

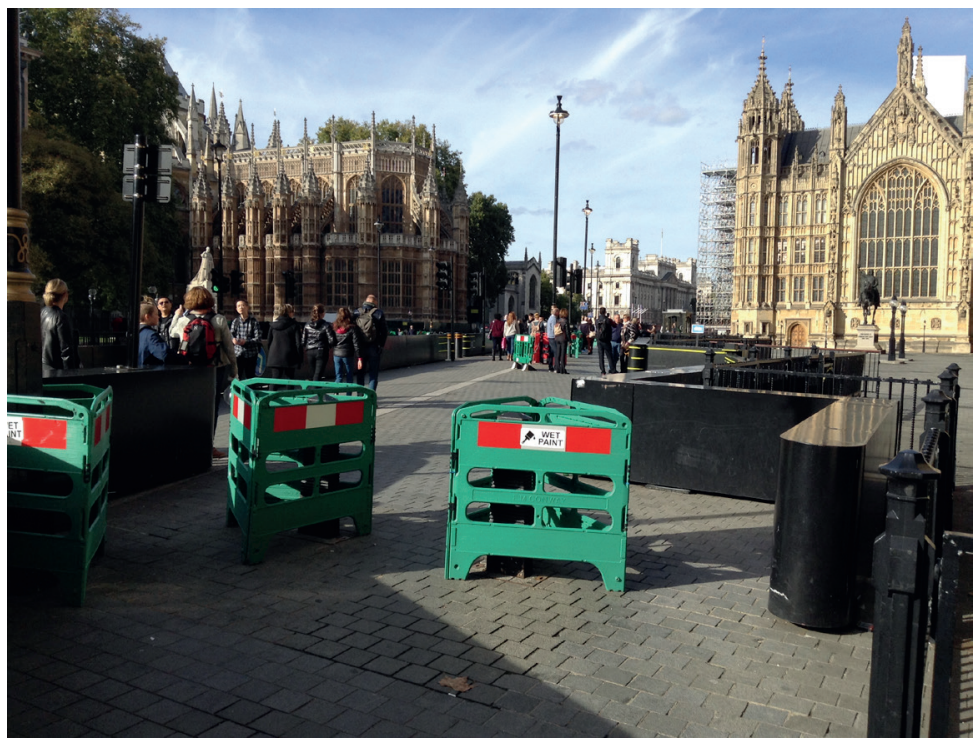

Fig. 3. Temporary counter-terrorism measures in London's streets (Source: Author)

\section{COUNTER-TERRORIST ADJUSTMENTS IN SHARED SPACE}

Based on the consultations held at the CPNI and CIHT, it was revealed that the counter-terrorism measures used on the classic streets and in Shared spaces are founded on the same principles: That is, calming the transport and protecting the sidewalks (in the case of Shared space the so-called safe zones). The following should be taken into consideration when discussing Shared space: The measure of demarcation of these zones is determined depending on the specific situation, the intensity of traffic and 
the number of pedestrians. Lastly, even absolute integration can be achieved, even when there is no clear separation between safe zones and zones with mixed traffic. It can be assumed that this situation poses the greatest danger from a counter-terrorist point of view, since pedestrians in this case do not distinguish between mixed and safe zones and may linger more on the so-called carriageway, where they are in danger of a vehicle-borne attack. Thus it can be concluded that from a safety point of view, Shared space should still have a minimal demarcation measure so that pedestrians can identify safe zones and zones with mixed traffic where there is a potential threat of collision.

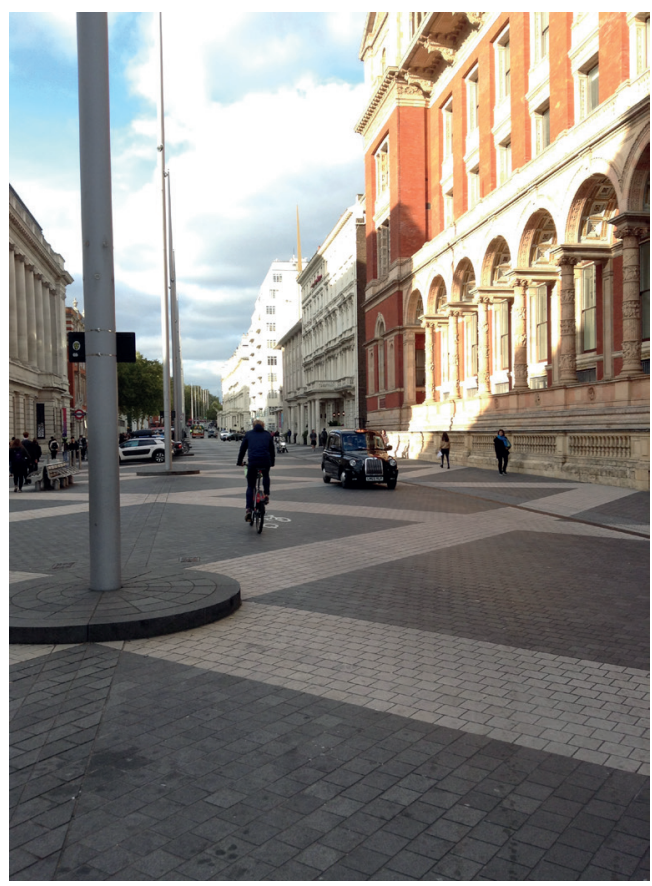

Fig. 4. Shared space without apparent boundaries, London, Exhibition Road (Source: Author)

Safety in areas near to building facades is based on the complete exclusion of vehicle access (based on the principle of Vehicle exclusion with the use of the static barriers suggested by this approach). Bollards are the most common tool utilized here, as they are more flexible in the context of design and grant pedestrians high levels of accessibility and mobility. Other tools that can be used include walls, fences, columns, steel furniture, sculptural forms, landscape forms, raised planters and other elements integrated into street design. The main condition is that the foundation must be deeply 
buried in the ground or represent a heavy steel platform lying under the road surface (this is convenient in cases when communication cables run beneath it it). It was found that tree-shaped barriers are not a hindrance to a fast-moving car, nor are curbs or raised sidewalks with a height below half a meter.

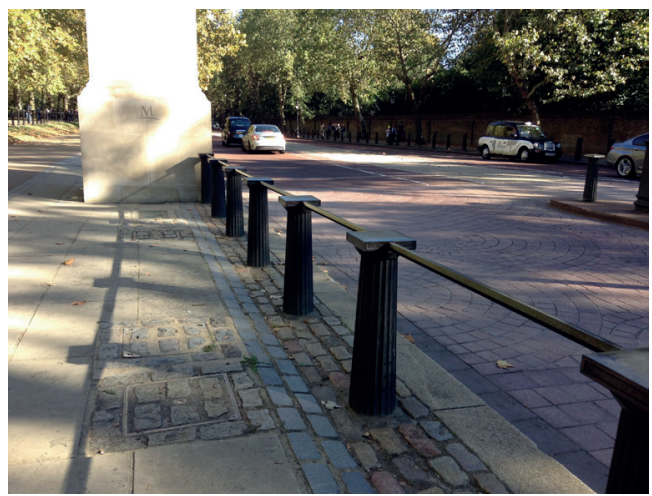

Fig. 5. Bollards in London's streets (Source: Author)

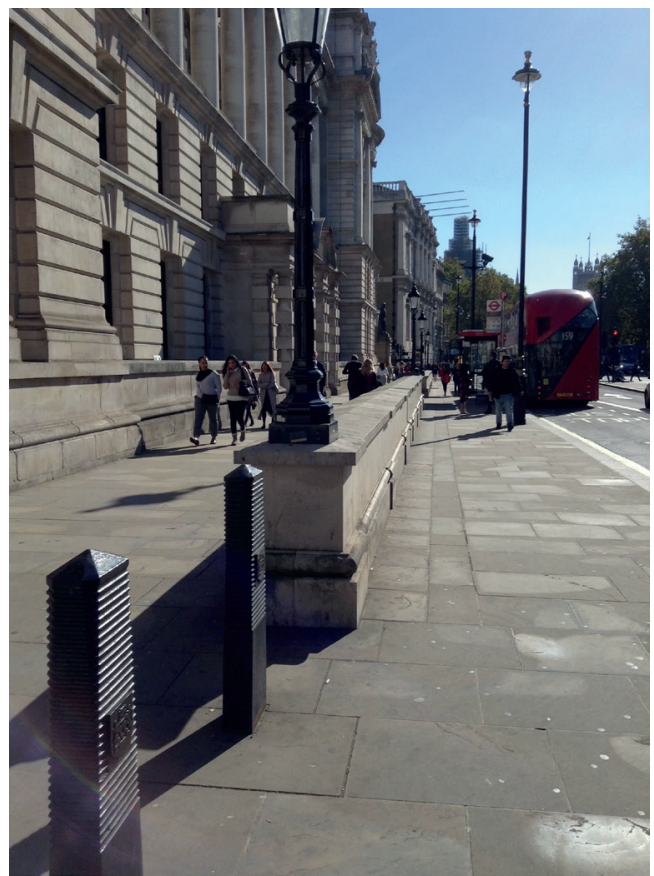

Fig. 6. Another counter-terrorism element in London's streets (Source: Author) 


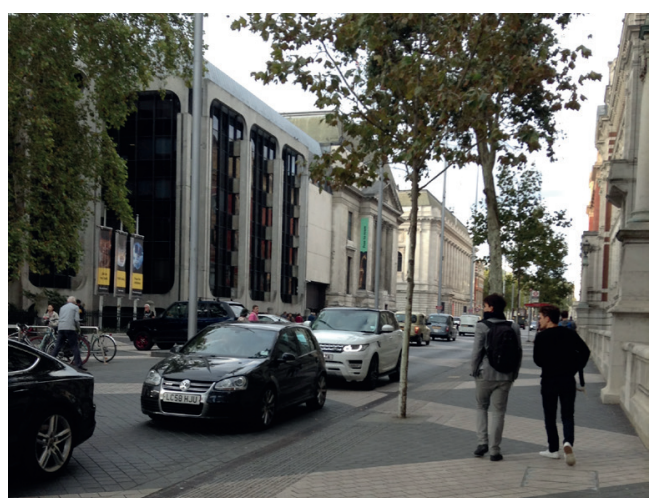

Fig. 7. Trees in Shared space, London, Exhibition Road (Source: Author)

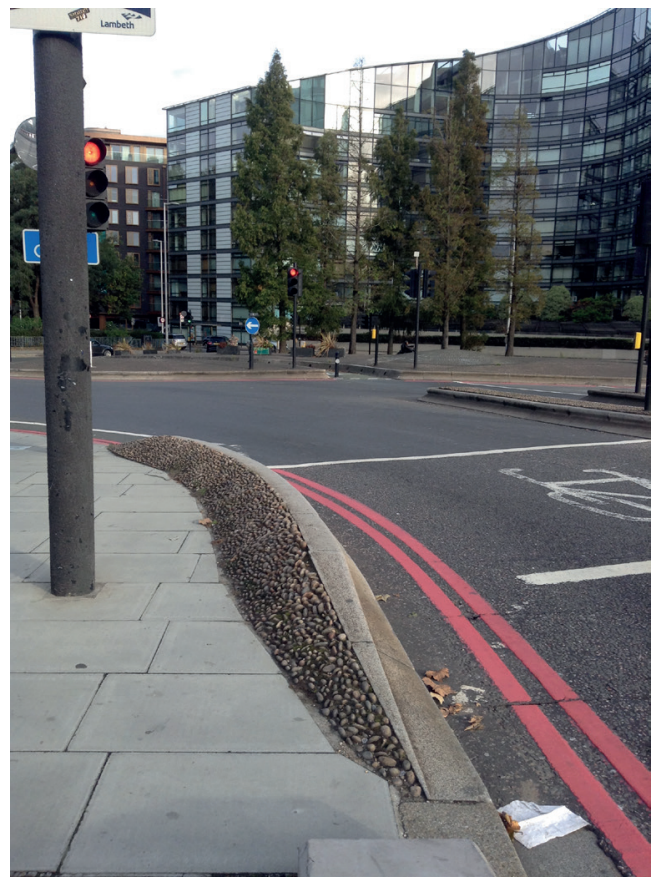

Fig. 8. Raised curbs on London's streets (Source: Author)

Safety against vehicle-borne attacks in a mixed traffic area in Shared space presents more of a challenge. Traffic in these areas is not limited as there is no separation be- 
tween cars and pedestrians. Despite this, counter-terrorism measures should also be applied in cases where the level of traffic is quite low. One of the approaches utilized is the Traffic Calming method: Bends and chicanes are formed by flower beds and other vertical structures that prevent cars from accelerating. The latter, however, can create complexity in a Shared space on central city streets where the level of traffic is more intense and changing the trajectory of movement is inappropriate. In this case, a common tactic is to narrow the space with mixed movement (for example, with help columns) to a width where the car can only move along a designated corridor, and it is not difficult for pedestrians to safely cross the zone with mixed movement, moving mainly in wider safe (comfortable) areas.

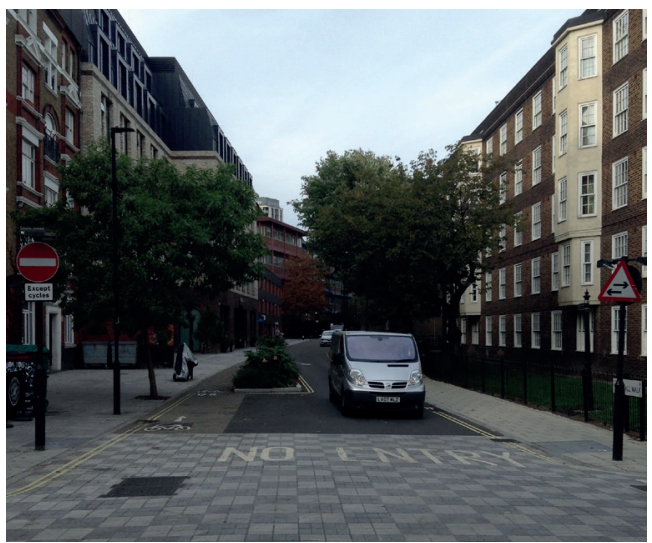

Fig. 9. Bends and chicanes on London's streets (Source: Author)

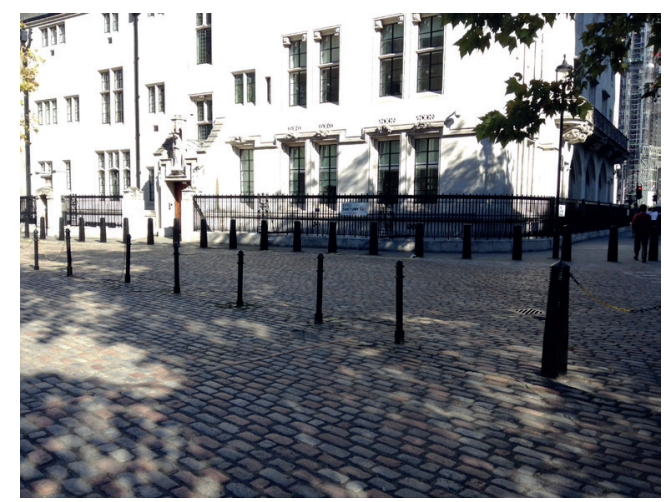

Fig. 10. Shared space with corridor for car, London (Source: Author)

The implementation of any of the listed physical measures in urban infrastructure is accompanied by a number of specific requirements that they must comply with. 
The CPNI ${ }^{4}$ highlights the following: Aesthetics, Public Access, Traffic Management, Physical Constraints, Health \& Safety, Cost and Maintenance. To do this, it is very important that a multidisciplinary approach is followed. So that such measures do not cause fear and a sense of danger in people, the counter-terrorism elements utilized are masked in street design and engineering solutions allow to facilitate the construction physically and visually.

\section{CONCLUSIONS}

Throughout the research, it was determined that no special counter-terrorism measures for spaces like Shared space were found up to now. The acute issue for counter-terrorism measures in the Shared space is the mixed traffic zone, where cars, pedestrians and cyclists are integrated in one common space. It was revealed that the minimum level of segregation should still be maintained. This is necessary so that mixed traffic zones can be easily distinguished from safe zones as a zone with an increased danger of a vehicle-borne terrorist attack. From a safety perspective, an area with mixed traffic should be as narrow as possible and should also be limited (e.g. by bollards). Furthermore, special attention should be paid to the integration of all counter-terrorism measures into street design, so as not to destroy the quality of urban spaces. An adequate, proportional approach to potential threats is important in organizing counter-terrorism measures. It was also revealed that the current biggest challenge for Shared space and the fight against vehicle-borne attacks are autonomous vehicles. A lot of questions related to their interaction with pedestrians, cyclists, people in wheelchairs and people with vision loss must be researched, including the risks associated with using autonomous vehicles for terrorist attacks.

\section{References}

DFT, 2011. Local transport note: Shared space (1/11). London: TSO (The Stationery Office). ISBN 9780115532092.

HAMILTON-BAILLIE, Ben, 2008. Shared space: Reconciling people, places and traffic [online]. UK: Scopus: Built Environment, 34(2), 161-181 [cit. 2017-08-24]. ISSN 02637960. Dostupné z: http://www.solaripedia.com/files/1233.pdf.

JACOBS, Jane, c1961. The death and life of great American cities. New York: Vintage Books. Vintage books, V-241.

PPS, 2008. Allan Jacobs. Placemaking heroes [online]. DEC 31, 2008, 2008 [cit. 2018-0312]. Dostupné z: https://www.pps.org/article/ajacobs. 


\section{Notes}

1 Prof. Jon Coaffee, "A brief history of urban anti-terrorism measures", 2017

2 Allan Jacobs, Placemaking heroes, 2008

3 Jane Jacobs, The death and life of great American cities, 1961

4 CPNI, Integrated security, 2nd edition, 2014 